陶敏, 岳兴建, 岳珊, 代丽娜, 韩文文, 王永明, 刘果, 李斌.四川丘陵区水库浮游植物群落结构与蓝藻水华风险——基于优势种生态位与种间联结 研究.生态学报,2021,41(23):9457-9469.

Tao M, Yue X J, Yue S, Dai L N, Han W W, Wang Y M, Liu G, Li B.Phytoplankton community structure and cyanobacteria bloom risk of reservoirs in hilly regions of Sichuan Province based on dominant species niche and interspecific association. Acta Ecologica Sinica, 2021, 41(23):9457-9469.

\title{
四川丘陵区水库浮游植物群落结构与蓝藻水华风险
} 基于优势种生态位与种间联结研究

\author{
陶 敏 ${ }^{1,2}$, 岳兴建 ${ }^{1,2}$, 岳 珊 ${ }^{1}$, 代丽娜 ${ }^{1}$, 韩文文 ${ }^{1}$, 王永明 ${ }^{1,2}$, 刘 果 ${ }^{1}$, 李 斌 ${ }^{1,2}$, * \\ 1. 内江师范学院,生命科学学院, 内江 641112 \\ 2. 长江上游鱼类资源保护与利用四川省重点实验室，内江 641112
}

\begin{abstract}
摘要: 为了解四川丘陵区中小型水库浮游植物群落结构周年变化, 掌握其演替规律并预测其发展方向, 于 2016 年一 2017 年分 季节对该地区 10 个典型水库进行了周年研究。结果显示: 共检出浮游植物 9 门 104 属 188 种, 其中优势种 4 门 16 属 16 种, 以 湖泊假鱼腥藻 (Pseudanabaena linmnetica) 优势度指数为最高; 蓝藻密度在各季节、各水库中均占据优势, 尤其是夏季。优势种生 态位宽度和生态位重叠度在存在明显的季节差异性, 并受到水温、营养条件等环境因子的显著影响; 优势种可分为 3 个类别, 竞 争力相对较强的 7 个种中有 5 种蓝藻; 全年发展性最强的种类也多为蓝藻,特别是湖泊假鱼腥藻等具有产毒潜力的种类,其优 势度存在进一步扩大的风险。种间联结性检验结果显示,群落种间大致表现出净的正联结,优势种种对间正负关联比大于 1 , 该类水库群落结构较为稳定且存在正向演替的趋势,可能会导致夏季间断性产毒蓝藻水华的风险。研究结果可为四川丘陵区 中小型水库浮游植物群落演替研究以及蓝藻水华预警提供基础资料。
\end{abstract}

关键词: 四川省; 中小型水库;浮游植物;蓝藻;生态位;种间联结

\section{Phytoplankton community structure and cyanobacteria bloom risk of reservoirs in hilly regions of Sichuan Province based on dominant species niche and interspecific association}

TAO Min ${ }^{1,2}$, YUE Xingjian ${ }^{1,2}$, YUE Shan ${ }^{1}$, DAI Lina ${ }^{1}$, HAN Wenwen ${ }^{1}$, WANG Yongming ${ }^{1,2}$, LIU Guo ${ }^{1}$, LI Bin ${ }^{1,2, *}$

1 School of Life Sciences, Neijiang Normal University, Neijiang 641112, China

2 Conservation and Utilization of Fishes resources in the Upper Reaches of the Yangtze River, Key Laboratory of Sichuan Province, Neijiang 641112, China

\begin{abstract}
Sichuan is known as a province with thousands of rivers and numerous reservoirs which play an important role in production and life. There is a general problem of pollution in small and medium-sized reservoirs in this area, which may affect the structure, function and utilization of aquatic ecosystem. Aiming to explore the annual changes and succession rules of phytoplankton community structure in small and medium-sized reservoirs in hilly regions of Sichuan Province and to predict its development direction, this study conducts an annual survey on 10 typical reservoirs in specific regions in different seasons from 2016 to 2017. The survey identifies a total of 188 species of phytoplankton in 104 genera of 9 phyla, including 16 species ( 9 species are cyanobacteria) of 16 genera of 4 phyla which are identified as dominant species. In particular, the dominance index of Pseudoanabaena linmnetica is the highest, and the density of cyanobacteria is dominant
\end{abstract}

基金项目:四川省科技厅项目(2019YJ0498，2019YJ0397);四川省教育厅重点项目(18ZA0277)

收稿日期: 2020-08-18; 网络出版日期:2021-07-26

*通讯作者 Corresponding author.E-mail: libin2004xinyang@126.com 
in all seasons and reservoirs, especially in summer. Furthermore, the improved Levins formula and Petraitis index are applied to determine the niche metrics of the phytoplankton dominant species. The results show that the niche breadth and niche overlap of each dominant species vary seasonally and are significantly affected by water temperature and nutrient. Based on their niche breadth in different seasons, the dominant species are classified into three categories, two of which are relatively competitive. These two categories include 7 species, of which there are 5 species of cyanobacteria, including P. linmnetica. The dominant species in four seasons are mostly in a state of developing, and the most promising species throughout the year are mainly cyanobacteria. In particular, species with the potential to produce toxins such as $P$. linmnetica have the risk of further expansion of their dominance. The results of interspecific association show a positive correlation among the community species throughout the year, indicating that the community structure in these reservoirs is relatively stable and there is a positive succession trend. In such a trend, intermittent toxic cyanobacteria bloom which affects the quality and function of water may occur in these reservoirs in summer, especially in reservoirs with simple dominant species composition. This paper provides research background for the study of phytoplankton community succession and the early warning of cyanobacteria blooms in small and medium-sized reservoirs in hilly regions of Sichuan Province. To prevent possible filamentous cyanobacteria bloom outbreak, water quality of the reservoirs should be effectively managed and immediately repaired under the dual promotion of high nutritional level and global warming.

Key Words: Sichuan province; small and medium-sized reservoirs; phytoplankton; cyanobacteria; niche; interspecific association

物种生态位理论与种间联结性理论能解释自然群落中不同物种共存与竞争机制, 对研究群落结构功能、 群落内种间关系、群落演替、种群进化等方面具有指导意义 ${ }^{[1-2]}$ 。生态位测度包括生态位宽度和生态位重叠 两个指标, 其中生态位宽度为反映物种所能利用的各种资源的一个综合指标 ${ }^{[3]}$, 生态位重叠则反映两个物种 对同一资源的利用效率及共享程度 ${ }^{[4]}$, 二者被认为是物种多样性及群落结构的决定因素,也反映了其所在群 落的稳定性 ${ }^{[5]}$ 。种间联结体现了物种与物种之间在分布上的关联, 是群落重要的结构特征与数量特征, 也是 群落结构形成与发生演化的基础 ${ }^{[6]}$ 。浮游植物是水域生态系统中的重要初级生产者, 其群落结构与动态直 接影响并反映着生态系统的稳定性, 关系着水体的健康与功能。对浮游植物优势种生态位与种间联结性开展 相关研究, 不仅可以帮助了解群落内各种群对资源的利用情况, 而且有助于掌握种群的竞争机制和竞争规律, 揭示浮游植物适应性特征与环境变化之间的关系 ${ }^{[7-9]}$, 预测环境变化乃至全球环境变化对群落结构的影 响 ${ }^{[10-12]}$ 。目前关于浮游植物生态位相关研究较少, 主要集中于海洋 ${ }^{[7-8,11-15]}$ 。另外在湖泊、河流等淡水水域中 也有少量相关研究 ${ }^{[2,9,16-20]}$ 。

四川丘陵地区降水分布不均 ${ }^{[21]}$, 资源性缺水及工程性缺水严重 ${ }^{[22]}$, 故而水库在该地区人民生产生活中 扮演着极其重要的角色。截至 2011 年底, 四川省已建总库容 10 万 $\mathrm{m}^{3}$ 及以上水库工程共 8072 座, 其中大型 水库 51 座, 中型水库 219 座, 小型水库 7878 座 ${ }^{[23]}$; 多数水库承担着当地居民饮用水源和农业灌溉的重任 ${ }^{[23]}$ 。 与大型水库不同, 中、小型水库由于水体容量小、自净力较弱、受工农业以及人类生活影响较大, 水质情况往往 不容乐观, 富营养化与藻类水华爆发的风险较高。因此, 本文选择四川丘陵区典型中、小型水库为研究对象, 通过生态位理论和种间联结法, 分析浮游植物群落中优势种利用资源的能力和在环境中的适应能力, 探寻优 势种间相互作用的生态关系与发展方向, 并据此预测该类水库中发生蓝藻水华的可能性, 为该地区水库水源 保护与生态修复提供科学依据。

\section{1 材料与方法}

1.1 研究水库概况与采样点设置

研究的 10 座代表性水库位于四川省东南丘陵地区。该区域地处长江上游, 坐标 $104^{\circ} 15^{\prime}-105^{\circ} 26^{\prime} \mathrm{E}$ 、 
$29^{\circ} 11^{\prime}-30^{\circ} 2^{\prime} \mathrm{N}$, 地势呈不规则状展布, 海拔 $274-900 \mathrm{~m}$, 属台状低山丘陵地形。气候类型为亚热带湿润季风 气候,冬暖夏热, 年均温 $15-28^{\circ} \mathrm{C}$, 年降雨量约 $1000 \mathrm{~mm}, 60 \%$ 分布在夏季 ${ }^{[24-25]}$ 。

10 座水库 (图 1) 中有中型水库 5 座、小型水库 5 座, 大坝坐标范围 $29^{\circ} 20^{\prime} 02^{\prime \prime} \mathrm{N}-29^{\circ} 54^{\prime} 51^{\prime \prime} \mathrm{N}, 104^{\circ} 37^{\prime}$ $12^{\prime \prime}-105^{\circ} 15^{\prime} 42^{\prime \prime} \mathrm{E}$, 总库容 $1.7 \times 10^{5}-7.58 \times 10^{7} \mathrm{~m}^{3}$ (表 1 )。按面积与形状, 在每个水库中设置 1 - 5 个采样点, 其中库容大于 $500 \times 10^{5} \mathrm{~m}^{3}$ 的设置 5 个采样点, $100 \times 10^{5}-500 \times 10^{5} \mathrm{~m}^{3}$ 的设置 4 个, $10 \times 10^{5}-100 \times 10^{5} \mathrm{~m}^{3}$ 的设置 3 个,库容最小的五星水库设置 1 个样点,于 2016 年 8 月(夏)、2016 年 11 月(秋),2017 年 2 月(冬)和 2017 年 5 月 (春) 分季节开展采样工作。

表 1 研究水库概况

Table 1 The basic information of reservoirs surveyed

\begin{tabular}{|c|c|c|c|c|c|}
\hline $\begin{array}{l}\text { 序号 } \\
\text { Number }\end{array}$ & $\begin{array}{l}\text { 水库名称 } \\
\text { Reservoir }\end{array}$ & $\begin{array}{l}\text { 规模 } \\
\text { Scale }\end{array}$ & $\begin{array}{l}\text { 总库容 } /\left(\times 10^{5} \mathrm{~m}^{3}\right) \\
\text { Total reservoir capacity }\end{array}$ & $\begin{array}{c}\text { 大坝坐标 } \\
\text { Latitude and longitude }\end{array}$ & $\begin{array}{c}\text { 采样点数/个 } \\
\text { Number of sampling points }\end{array}$ \\
\hline 1 & 葫芦口水库 & 中型 & 758.0 & $29^{\circ} 35^{\prime} 48^{\prime \prime} \mathrm{N}, 104^{\circ} 37^{\prime} 12^{\prime \prime} \mathrm{E}$ & 5 \\
\hline 2 & 古宇湖 & 中型 & 559.6 & $29^{\circ} 20^{\prime} 02^{\prime \prime} \mathrm{N}, 105^{\circ} 15^{\prime} 42^{\prime \prime} \mathrm{E}$ & 5 \\
\hline 3 & 龙江水库 & 中型 & 241.8 & $29^{\circ} 54^{\prime} 51^{\prime \prime} \mathrm{N}, 105^{\circ} 01^{\prime} 39^{\prime \prime} \mathrm{E}$ & 4 \\
\hline 4 & 松林水库 & 中型 & 145.3 & $29^{\circ} 42^{\prime} 22^{\prime \prime} \mathrm{N}, 105^{\circ} 07^{\prime} 14^{\prime \prime} \mathrm{E}$ & 4 \\
\hline 5 & 黄河水库 & 中型 & 145.0 & $29^{\circ} 31^{\prime} 39^{\prime \prime} \mathrm{N}, 104^{\circ} 54^{\prime} 55^{\prime \prime} \mathrm{E}$ & 4 \\
\hline 6 & 八一水库 & 小(1)型 & 66.0 & $29^{\circ} 35^{\prime} 44^{\prime \prime} \mathrm{N}, 104^{\circ} 54^{\prime} 56^{\prime \prime} \mathrm{E}$ & 3 \\
\hline 7 & 菜子沟水库 & 小(1) 型 & 55.0 & $29^{\circ} 36^{\prime} 42^{\prime \prime} \mathrm{N}, 104^{\circ} 41^{\prime} 24^{\prime \prime} \mathrm{E}$ & 3 \\
\hline 8 & 严家滩水库 & 小(1)型 & 47.2 & $29^{\circ} 23^{\prime} 10^{\prime \prime} \mathrm{N}, 105^{\circ} 10^{\prime} 12^{\prime \prime} \mathrm{E}$ & 3 \\
\hline 9 & 乌龟山水库 & 小(1) 型 & 25.0 & $29^{\circ} 48^{\prime} 20^{\prime \prime} \mathrm{N}, 104^{\circ} 52^{\prime} 15^{\prime \prime} \mathrm{E}$ & 3 \\
\hline 10 & 五星水库 & 小(1) 型 & 1.7 & $29^{\circ} 36^{\prime} 57^{\prime \prime} \mathrm{N}, 105^{\circ} 03^{\prime} 27^{\prime \prime} \mathrm{E}$ & 1 \\
\hline
\end{tabular}

1.2 样品采集、处理与测定

采样点透明度 (Secchi Depth, SD)、水温 (Water temperature, WT)、 $\mathrm{pH}$ 等理化指标使用塞氏盘、便携式 $\mathrm{pH}$ 计(METTLER TOLEDO Seven2Go) 等设备进行原位测定。总氮 (Total nitrogen, TN)、总磷 (Total phosphorus, $\mathrm{TP})$ 样品采集与测定参考相关文献 ${ }^{[26]}$ 在实验室中进行。浮游植物定量以 $5 \mathrm{~L}$ 有机玻璃定深采水器采集, 将 $1 \mathrm{~L}$ 表层 (水下 $0.5 \mathrm{~m}$ ) 水样装人 $1 \mathrm{~L}$ 样品瓶并立即加人鲁哥试剂现场固定。浮游植物定性样品用 25 号浮游生物网 $(0.064 \mathrm{~mm})$ 在水面下作“ $\infty$ ” 字形捞取并过滤收集,加人 $4 \%$ 甲醛现场固定。回到实验室后将浮游植物定量样 品在 $1 \mathrm{~L}$ 规格浮游生物沉淀器中避光静置沉降 $48 \mathrm{~h}$, 以虹吸法去除上层清液后, 浓缩定容至 $50 \mathrm{~mL}$, 加人数滴 甲醛溶液保存。种类鉴定参考胡鸿钧等 ${ }^{[27]}$, 计数方法参照章宗涉等 ${ }^{[28]}$ 。

\section{3 数据处理与分析}

\subsection{1 优势种确定}

浮游植物优势种以 Mcnaughton 优势度指数 $(Y)$ 值进行鉴别 ${ }^{[2]}$ :

$$
Y=P_{i} \times f_{i}
$$

式中, $P_{i}$ 为第 $i$ 种浮游植物丰度与样品中浮游植物总丰度的比值 $\left(n_{i} / N\right), f_{i}$ 为第 $i$ 种在各采样点出现的频度。 $Y \geqslant 0.02$ 的物种为优势种。

\subsection{2 生态位宽度}

采用修正后的 Levins 指数计算优势种生态位宽度 ${ }^{[2]}$ :

$$
B_{i}=\frac{1}{\left(r \sum_{j=1}^{r} P_{i j}\right)^{2}}
$$

式中, $B_{i}$ 为第 $i$ 种的生态位宽度, $P_{i j}=n_{i j} / N_{i}$, 为第 $i$ 种在第 $j$ 个样点出现的个体数占该种所有个体数的比例, $r$ 为样点数。 

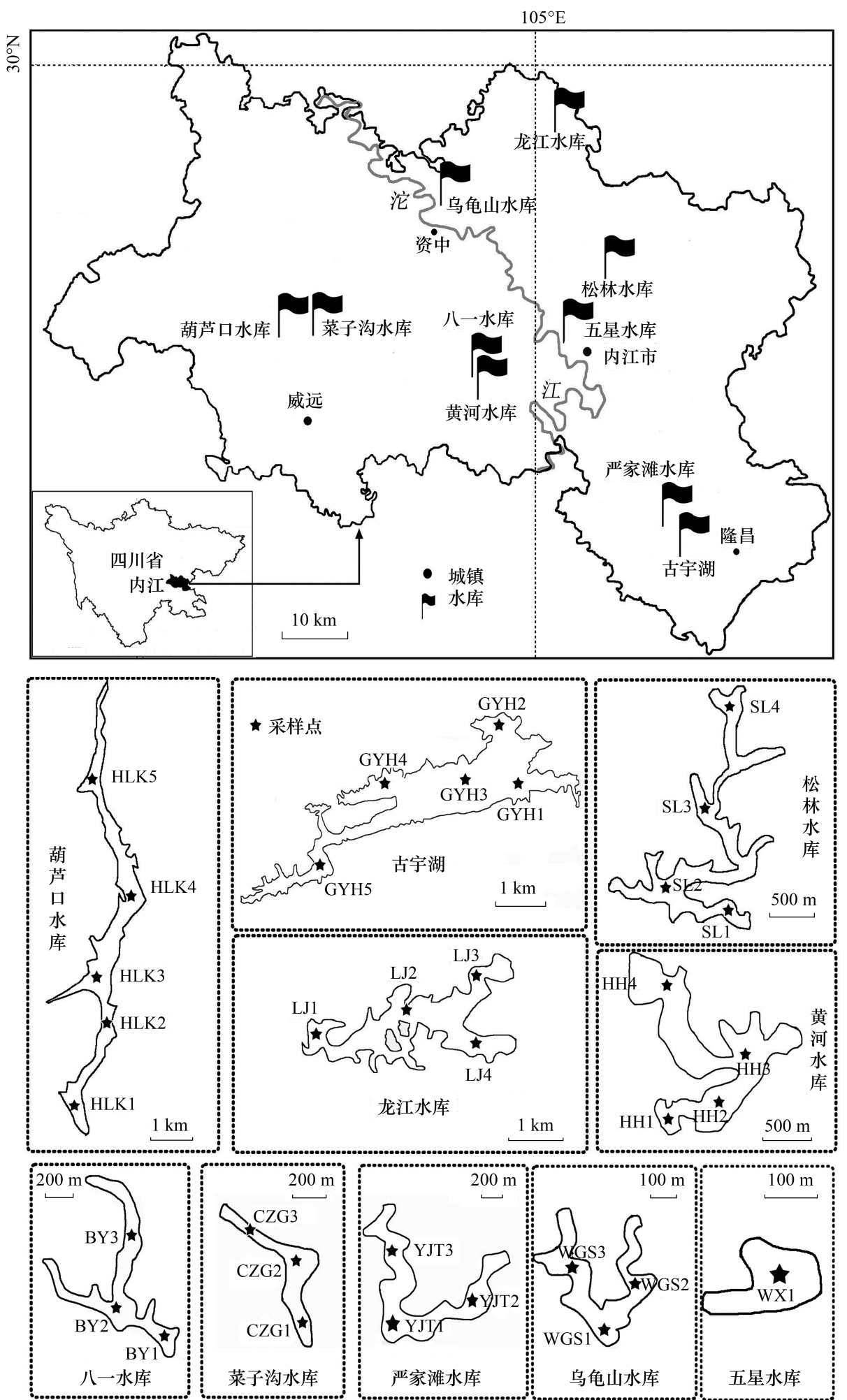

图 1 研究水库及采样点分布图

Fig.1 Distribution of reservoirs and sampling sites surveyed

$\mathrm{HLK}$ : 葫芦口水库; GYH: 古宇湖; LJ: 龙江水库; SL: 松林水库; HH: 黄河水库; BY: 八一水库; CZG: 菜子沟水库; YJT: 严家滩水库; WGS: 乌龟山水库; WX: 五星水库; 1-5: 各水库采样点编号 


\subsection{3 生态位重叠与生态响应速率}

采用 Petraitis 指数计算优势种之间的生态位重叠 ${ }^{[2]}$ :

$$
\begin{aligned}
& S O_{i k}=e^{E i k} \\
& E_{i k}=\sum_{j=1}^{r}\left(P_{i j} \ln P_{k j}\right)-\sum_{j=1}^{r}\left(P_{i j} \ln P_{i j}\right) \\
& \Delta S O_{i j}=\sum_{j=1}^{n} S O_{i j}-\sum_{i=1}^{m} S O_{i j} \\
& R_{i}=\frac{B_{i}}{\Delta S O_{i j}}
\end{aligned}
$$

式中, $S O$ 为成对种间生态位特定重叠, $k$ 为不同于 $i$ 的另一浮游植物物种, $S O_{i j}$ 表明物种对资源的利用程度, $R_{i}$ 为生态响应速率。

\subsection{4 物种间总体关联性}

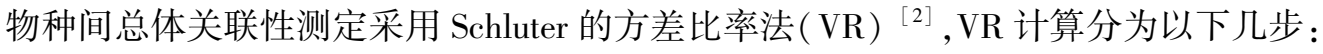

$$
\begin{aligned}
\delta T^{2} & =\sum_{i=1}^{s} P_{i}\left(1-P_{i}\right) \\
S T^{2} & =\frac{1}{N} \sum_{j=1}^{N}\left(T_{j}-t\right)^{2} \\
V R & =\frac{S T^{2}}{\delta T^{2}}
\end{aligned}
$$

式中, $S$ 为浮游植物优势种的总种类数; $P_{i}=n_{i} / N$, 其中 $N$ 表示样方总数, $n_{i}$ 表示物种 $i$ 出现的样方数; $T_{j}$ 表示 样方 $j$ 内出现的浮游植物优势种种数; $t$ 表示样方中浮游植物优势种物种数的平均数 $t=\left(T_{1}+T_{2}+\cdots+T_{n}\right) / N$; $\delta T^{2}$ 为所有采样点物种数的方差; $\mathrm{S} T^{2}$ 表示总种数出现频度的方差。

当 $V R=1$ 时,符合所有物种无关联的零假设; 当 $V R<1$ 时,物种间总体为负协变关系; 当 $V R>1$ 时,物种间 总体为正协变关系。利用统计量 $W=V R \times N$ 来检验 VR 值偏离 1 的显著程度, 在物种间总体无关联的情况下, $\chi_{0.95}^{2} N<W<\chi_{0.05}^{2} N$ 的概率有 $90 \%$ 。

\subsection{5 优势种种对间关联}

根据物种在样方内是否存在,将全年 207 个样点 $\times 16$ 个优势种的数量数据矩阵转化为 0,1 形式的二元 数据矩阵 ${ }^{[29]}$ 。基于 $2 \times 2$ 列联表, 采用 Yates 连续校正法, 进行 $\chi^{2}$ 卡方检验 ${ }^{[30]}$, 其计算公式如下:

$$
\chi^{2}=\frac{N[|a d-b c|-0.5 N]^{2}}{(a+b)(a+c)(b+d)(c+d)}
$$

$\chi^{2}<3.84(P>0.05)$, 表示物种间无显著关联性; $3.841 \leqslant \chi^{2} \leqslant 6.635(0.01 \leqslant P \leqslant 0.05)$ 表示物种间关联显著; $\chi^{2}>6.635(P<0.01)$ 则表示物种间关联性极显著。

\section{2 结果与讨论}

2.1 四川丘陵水库浮游植物群落结构

调查期间共检出浮游植物 9 门 104 属 188 种, 其中绿藻门出现的种类最多为 48 属 84 种, 占 $44.7 \%$, 其次 为硅藻门 (15 属 35 种, 占 $18.6 \%$ ) 和蓝藻门(19 属 34 种, 占 $18.1 \%$ )。其余门类种类数均较少, 包括裸藻门 5 属 12 种, 金藻门 8 属 10 种, 甲藻门 4 属 7 种, 隐藻门 2 属 4 种, 种类数最少的黄藻门和定鞭藻门, 均只出现 1 属 1 种, 仅占 $0.5 \%$ 。从种类数来看, 研究水库浮游植物群落组成与长江上游其他河流型水库近似, 以绿藻+硅 藻+蓝藻为主 ${ }^{[31-36]}$, 绿藻、蓝藻等静水种类的增多, 暗示着水体的富营养化 ${ }^{[33,37]}$ 。

从现存量季节分布来看 (图 2), 夏季浮游植物密度达到最大, 为 $(2.85 \pm 3.54) \times 10^{8}$ 个 $/ \mathrm{L}$, 其后依次为秋季 
$(6.04 \pm 8.52) \times 10^{7}$ 个 $/ \mathrm{L}$ 、冬季 $(2.38 \pm 4.92) \times 10^{7}$ 个 $/ \mathrm{L}$ 和春季 $(2.11 \pm 2.84) \times 10^{7}$ 个 $/ \mathrm{L}$ 。蓝藻在四季均占据优势地 位, 其中占比最高的为夏季 $(2.78 \pm 3.53) \times 10^{8}$ 个 $/ \mathrm{L}$, 占 $97.6 \%$; 其次为秋季 $(4.95 \pm 8.19) \times 10^{7}$ 个 $/ \mathrm{L}(81.9 \%)$ 与春 季 $(1.81 \pm 2.67) \times 10^{7}$ 个 $/ \mathrm{L}(85.8 \%)$, 冬季最低 $(1.56 \pm 4.65) \times 10^{7}$ 个 $/ \mathrm{L}(64.1 \%)$ 。从现存量空间分布上看 $($ 图 2$)$, 10 个水库中浮游植物总密度超过 $10^{8}$ 个 $/ \mathrm{L}$ 的有 4 个, 超过 $10^{7}$ 个/ $\mathrm{L}$ 的有 5 个; 其中最高的为 WGS, 年均值为 $(2.39 \pm 5.18) \times 10^{8}$ 个 $/ \mathrm{L}$, 最低为 $\mathrm{HLK}$, 年均值为 $(5.11 \pm 6.51) \times 10^{6}$ 个 $/ \mathrm{L}$ 。各水库均以蓝藻占优势, 所占比例从 $55.3 \%$ (HLK) 到 $96.7 \%$ (WGS) 不等, 其中蓝藻所占比例超过 $95 \%$ 的有 3 个 (WGS、SL、LJ), 其他藻类仅有绿藻 在 HLK 中占一定优势 $(38.1 \%)$ 。与长江上游大型水库如紫坪铺、长寿湖、升钟湖、二滩水库等相比 ${ }^{[31-35]}$, 本研 究中的中小型水库浮游植物丰度高出 $2-3$ 个数量级, 按照相关评价标准 ${ }^{[38]}$, 夏季已达到极富营养水平, 秋季 为富营养水平, 冬春两季为中营养水平, 富营养化比大型水库更为明显。尽管蓝藻种类数明显少于绿藻和硅 藻, 但其丰度占据了绝对优势, 这一现象与长江上游流域部分水库类似 ${ }^{[36,39]}$, 爆发蓝藻水华的风险较高。
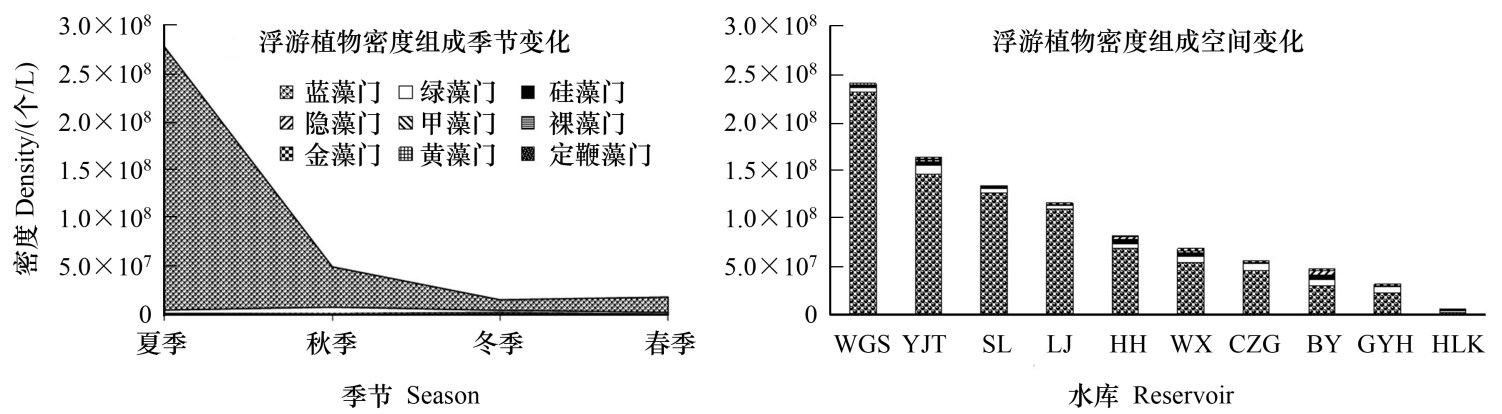

图 2 研究水库浮游植物密度时空分布

Fig.2 The temporal and spatial distribution of phytoplankton abundance

2.2 四川丘陵浮游植物群落优势种

四季共出现 4 门 16 个优势种 $(Y \geqslant 0.02)$, 其中蓝藻 9 种、绿藻 4 种、硅藻 1 种、隐藻 2 种; 以全年数据进行 分析, 结果显示优势种仅 3 种, 均为蓝藻 (表 2$)$ 。与蓝藻 $(Y$ 值跨度 $0.020-0.435$, 均值 $(0.124 \pm 0.136))$ 相比, 其他藻类 $(Y$ 值跨度 $0.020-0.056$, 均值 $(0.031 \pm 0.011))$ 优势度指数均不高 $(P=0.013$, 独立样本 $\mathrm{t}$ 检验 $)$ 。优

表 2 研究水库优势种优势度指数

Table 2 Dominance index of dominant phytoplankton species

\begin{tabular}{|c|c|c|c|c|c|c|c|c|c|c|c|c|}
\hline \multirow{2}{*}{$\begin{array}{l}\text { 编号 } \\
\text { Number }\end{array}$} & \multirow{2}{*}{$\begin{array}{l}\text { 优势种 } \\
\text { Dominant species }\end{array}$} & \multicolumn{2}{|c|}{ 夏季 Summer } & \multicolumn{2}{|c|}{ 秋季 Autumn } & \multicolumn{2}{|c|}{ 冬季 Winter } & \multicolumn{2}{|c|}{ 春季 Spring } & \multicolumn{2}{|c|}{ 全年 All year } & \multirow{2}{*}{$\begin{array}{l}\text { 优势季节 } \\
\text { Dominant season }\end{array}$} \\
\hline & & $\overline{f_{i}}$ & $Y$ & $\overline{f_{i}}$ & $Y$ & $\overline{f_{i}}$ & $Y$ & $\overline{f_{i}}$ & $Y$ & $\overline{f_{i}}$ & $Y$ & \\
\hline 1 & 湖泊假鱼腥藻 & $100 \%$ & 0.240 & $82.1 \%$ & 0.421 & $80.8 \%$ & 0.435 & $83.3 \%$ & 0.240 & $87.9 \%$ & 0.531 & 春、夏、秋、冬 \\
\hline 2 & 拉氏拟柱狍藻 & $93.1 \%$ & 0.091 & $35.7 \%$ & 0.020 & & & $50 \%$ & 0.158 & $46.7 \%$ & 0.032 & 春、夏、秋 \\
\hline 3 & 微小平裂藻 & $72.4 \%$ & 0.025 & $64.3 \%$ & 0.022 & & & & & & & 夏、秋 \\
\hline 4 & 拟短形颤藻 & $93.1 \%$ & 0.158 & $67.9 \%$ & 0.020 & & & & & $58.9 \%$ & 0.063 & 夏、秋 \\
\hline 5 & 中华小尖头藻 & $96.6 \%$ & 0.026 & $85.7 \%$ & 0.034 & & & & & & & 夏、秋 \\
\hline 6 & 大螺旋藻 & & & $64.3 \%$ & 0.061 & & & & & & & 秋 \\
\hline 7 & 卷曲鱼腥藻 & & & & & & & $70.8 \%$ & 0.091 & & & 春 \\
\hline 8 & 阿氏拟鱼腥藻 & & & & & & & $50 \%$ & 0.031 & & & 春 \\
\hline 9 & 细浮鞘丝藻 & $93.1 \%$ & 0.031 & & & & & & & & & 夏 \\
\hline 10 & 二形栅藻 & & & $100 \%$ & 0.020 & & & $91.7 \%$ & 0.026 & & & 春、秋 \\
\hline 11 & 短小塔胞藻 & & & & & $61.5 \%$ & 0.036 & & & & & 冬 \\
\hline 12 & 小环藻 & & & & & $84.6 \%$ & 0.056 & & & & & 冬 \\
\hline 13 & 小球藻 & & & & & $100 \%$ & 0.032 & $100 \%$ & 0.025 & & & 春、冬 \\
\hline 14 & 球衣藻 & & & & & $92.3 \%$ & 0.032 & & & & & 冬 \\
\hline 15 & 啮噬隐藻 & & & & & $80.8 \%$ & 0.020 & & & & & 冬 \\
\hline 16 & 尖尾蓝隐藻 & & & & & $76.9 \%$ & 0.029 & & & & & 冬 \\
\hline
\end{tabular}


势种组成说明了研究水库污染现状不容乐观: 种类数最多的蓝藻是最典型的富营养水体优势类群 ${ }^{[37]}$, 其他种 类则多为中污带指示生物或耐有机污染种类 ${ }^{[40]}$ 。

尽管优势种种类数较多,其优势度和密度在不同季节存在差异。除冬季以绿藻和隐藻为主要优势藻种 外, 其余 3 个季节均以蓝藻占多数, 尤其是丝状蓝藻 (表 2)。湖泊假鱼腥藻 (Pseudanabaena linmnetica) 在四季 都具有最高的优势度, 其年均密度 $\left((6.26 \pm 18.73) \times 10^{7}\right.$ 个 $\left./ \mathrm{L}\right)$ 和最高密度 $\left(1.84 \times 10^{8}\right.$ 个/L $)$ 也均是最高, 成为绝 对优势种。拉氏拟柱狍藻 (Cylindrospermopsis raciborskii) 除冬季外在其余 3 个季节均占优势地位, 尤其在春季 其密度为 16 种中最高 $\left((6.69 \pm 19.28) \times 10^{6}\right.$ 个 $\left./ \mathrm{L}\right)$ 。表 2 显示了藻类在不同季节中的优势分布情况, 大部分种 类 (9 种) 仅在某一季节成为优势种属 (表 2)。在三峡库区开展的研究也发现, 丝状蓝藻的优势普遍存 在 ${ }^{[36,39]}$, 尤其是夏季, 但冬春两季蓝藻优势度明显下降, 且优势种间优势度指数差异不大 ${ }^{[39]}$, 未形成如本研 究中湖泊假鱼腥藻这样的绝对优势, 可能跟三峡库区水体较大, 自我调节能力较强有关。

研究水库面临着同样的问题,即丝状蓝藻的普遍优势, 仅在程度上有所不同 (表 3):SL、LJ、HH、YJT、WGS 五个水库中的优势种组成较简单, 均以丝状蓝藻为主, 其密度高达 $7.2 \times 10^{7}-20.7 \times 10^{7}$ 个/L, 占浮游植物总密 度比例为 $78.9 \%-86.7 \%$; 其中 SL、LJ 和 WGS 三个水库假鱼腥藻优势度指数 $Y$ 高达 $0.63-0.85$, 优势种组成 单一, 爆发丝状蓝藻水华风险较高。HLK、GYH 和 BY 中丝状蓝藻的优势度则相对较低, 密度在 $2.1 \times 10^{6}-$ $13.3 \times 10^{6}$ 个/L 之间, 占比 $18.2 \%$ - $41.5 \%$, 优势种较多且优势度均不高, 表明其群落结构相对来说较复杂也较 为完整, 水华风险相对较低。相关分析发现不同水库丝状蓝藻优势与营养水平无关 $(P>0.05)$, 可能更多地取 决于水库大小、周边生产生活干扰、灌溉与泄洪频率等因素的综合作用。

\section{3 优势种生态位宽度}

生态位宽度 (niche breadth) 是反映群落中物种所能利用的各种资源的一个综合指标 ${ }^{[18,41]}$ 。生态位宽度大的 物种利用资源的能力强, 竞争力强, 被称为泛化种或广布种; 生态位宽度小的物种则相反, 被称为特化种 ${ }^{[42-43]}$ 。

从全年数据来看, 绿藻生态位宽度稳定且较大, 其中全年 $B_{i}$ 值以小球藻 (Chlorella vulgaris) 为最高 ( 图3)。四季中, 夏季以蓝藻生态位宽度值较大, $B_{i}$ 最高的为当季优势种细浮鞘丝藻 (Planktolyngbya subtilis)。

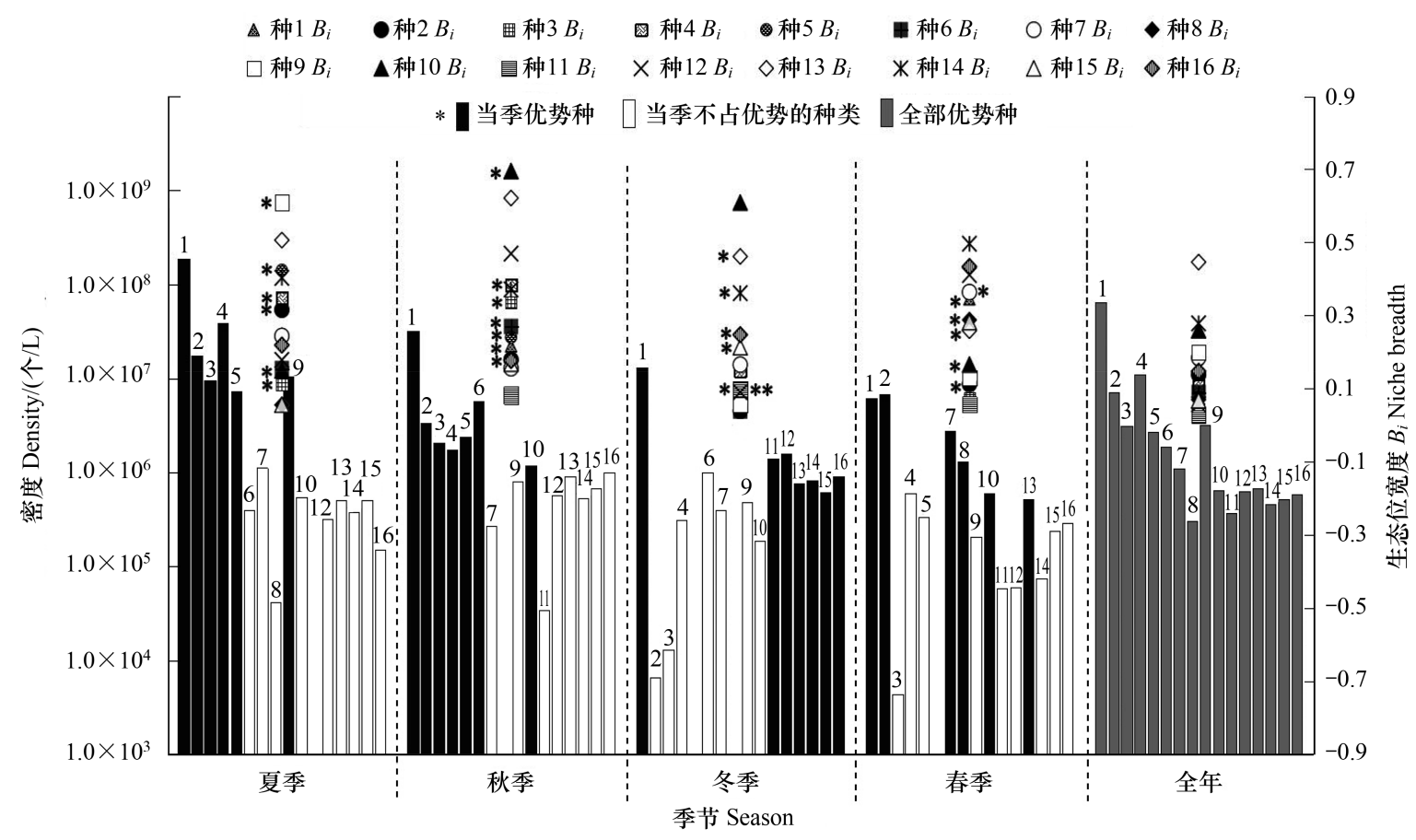

图 3 优势浮游植物密度与生态位宽度 $\left(\boldsymbol{B}_{i}\right)$

Fig.3 Abundance and niche breadth of dominant phytoplankton species 


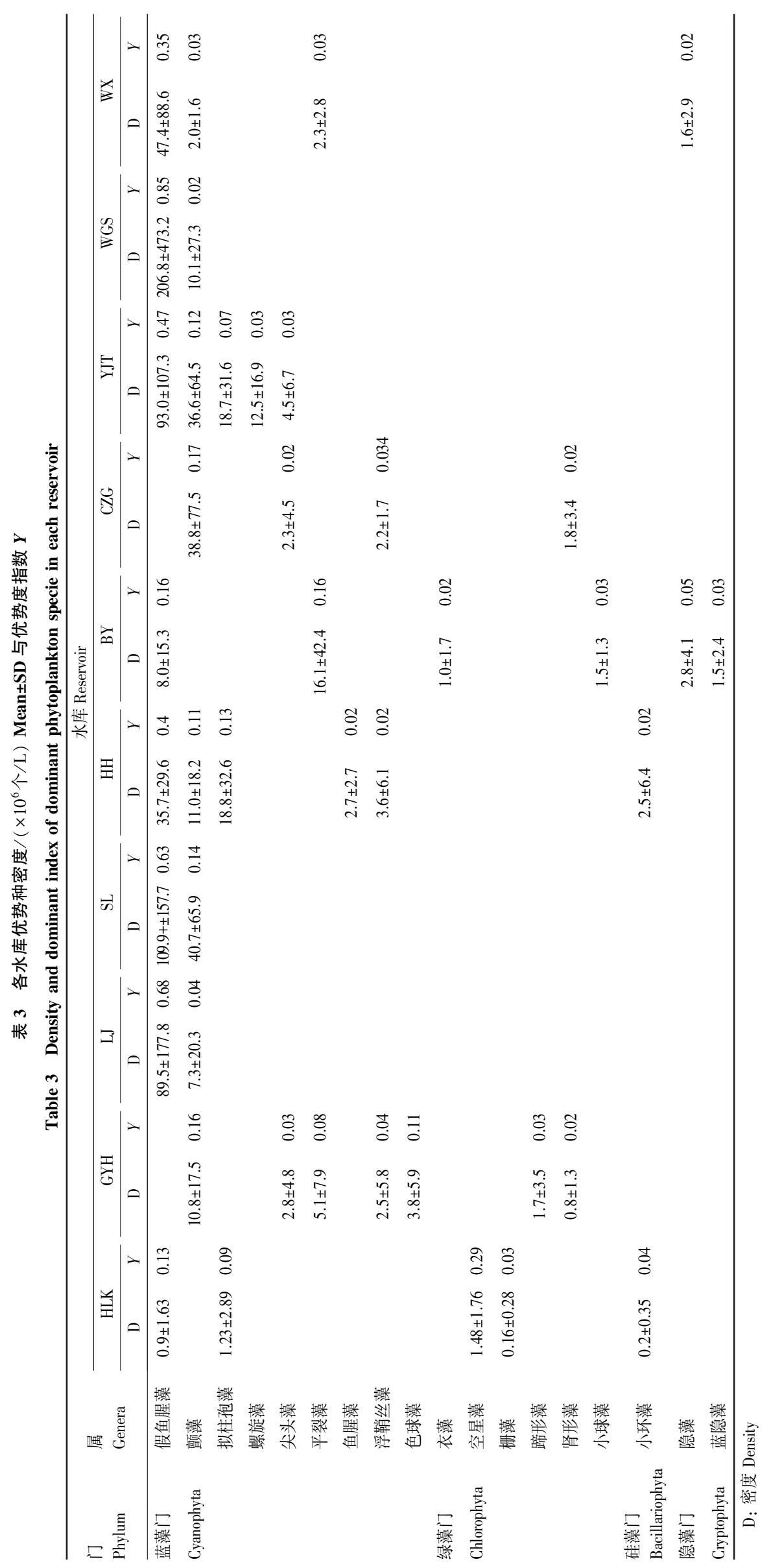


调查期间各季节理化指标均值见表 4。相关分析显示细浮鞘丝藻密度与水温显著正相关 $(R=0.62, P<0.01)$, 夏季高水温可能是其占据较宽生态位的主要原因 ${ }^{[19]}$ 。其余三个季节生态位宽度最大的均为绿藻, 其中秋、冬 季均为二形栅藻 (Scenedesmus dimorphus), 春季为球衣藻 (Chlamydomonas globosa)。研究发现, 冬季和春季 $B_{i}$ 值最高的种类均非当季优势种, 密度也较低 (图 3, 表 2); 尽管这些藻类藻数量少, 但由于其相对较宽的生态 适应幅度与顽强的竞争力,保证了它们在各种水体环境中生存与发展的可能性。而四季中均占有优势的湖泊 假鱼腥藻 $B_{i}$ 在春季最大 $(0.345)$, 冬季最小 $(0.09)$, 则可能与水温有关。有研究发现,富营养化水体中适宜的 水温 $\left(24-30^{\circ} \mathrm{C}\right)$ 是蓝藻暴发性增殖的必要条件 ${ }^{[19,44]}$ 。春季调查期间水温 $(26.5 \pm 2.6)^{\circ} \mathrm{C}($ 表 4$)$, 适宜其生长 故生态位宽度最大, 冬季水温最低 $(14.1 \pm 1.0)^{\circ} \mathrm{C}$ ( 表 4) 影响其增殖, 故生态位宽度最小。而其密度则在后一 个季节达到极值,如夏季最大 $(1.84 \pm 3.26) \times 10^{8}$ 个 $/ \mathrm{L}$, 春季最小 $(6.08 \pm 8.55) \times 10^{6}$ 个 $/ \mathrm{L}$, 可能是由于其种群发展 存在时滞所致。

表 4 研究水库环境因子季节变化 $(\mathrm{Mean} \pm \mathrm{SD})$

Table 4 Seasonal variations of environmental factors in studied reservoirs

\begin{tabular}{lcccc}
\hline $\begin{array}{l}\text { 环境因子 } \\
\text { Environmental factors }\end{array}$ & $\begin{array}{c}\text { 夏季 } \\
\text { Summer }\end{array}$ & $\begin{array}{c}\text { 秋季 } \\
\text { Autumn }\end{array}$ & $\begin{array}{c}\text { 冬季 } \\
\text { Winter }\end{array}$ & $\begin{array}{c}\text { 春季 } \\
\text { Spring }\end{array}$ \\
\hline 水温 Water temperature $/{ }^{\circ} \mathrm{C}$ & $30.900 \pm 1.2$ & $17.500 \pm 1.4$ & $14.100 \pm 1.0$ & $26.500 \pm 2.6$ \\
透明度 Secchi depth $/ \mathrm{cm}$ & $80.800 \pm 71.9$ & $132.100 \pm 94.3$ & $80.900 \pm 22.0$ & $84.600 \pm 19.5$ \\
$\mathrm{pH}$ & $8.700 \pm 0.5$ & $7.700 \pm 0.5$ & $8.300 \pm 0.3$ & $8.600 \pm 0.4$ \\
总氮 Total nitrogen $/(\mathrm{mg} / \mathrm{L})$ & $1.270 \pm 0.49$ & $3.390 \pm 0.92$ & $6.520 \pm 0.64$ & $1.860 \pm 0.63$ \\
总磷 Total phosphorus $/(\mathrm{mg} / \mathrm{L})$ & $0.198 \pm 0.179$ & $0.176 \pm 0.254$ & $0.896 \pm 0.533$ & $0.068 \pm 0.055$ \\
氮磷比 N/P ratio & $29.700 \pm 57.3$ & $51.700 \pm 52.1$ & $13.600 \pm 21.1$ & $40.500 \pm 29.3$ \\
\hline
\end{tabular}

综合各种在不同季节的出现频率与生态位宽度,将研究水库的优势种分为 3 类：

第一类为研究水库中相对泛化的种群,包括二形栅藻、小球藻和湖泊假鱼腥藻, 为全年生态位最宽或在各 个季节均作为优势种出现的种类。小球藻与栅藻在较多的研究中被证实具有较宽的生态位,属于广布 种 ${ }^{[2,18]}$ 。尽管湖泊假鱼腥藻生态位宽度值并不最高 $(0.090-0.345)$, 甚至冬季 $B_{i}$ 为所有优势种中最低值 ( 图 3 ), 但在优势度和密度方面,其季节均值和年均值均为所有藻类中最高。综合优势度、现存量、出现频率等因 素, 将湖泊假鱼腥藻也归为研究水库中相对泛化的类群。这三种藻类高度适应四川丘陵地区小型水库生态环 境,拥有强的适应力,其变化可对水库中藻类群落的结构及水环境状况产生重要影响。

第二类为中生态位优势种,包括拉氏拟柱狍藻、微小平裂藻 (Merismopedia tenuissima) 、拟短形颤藻 (Oscillatoria subbrevis)、中华小尖头藻 (Raphidiopsis Sinensia) 4 种蓝藻,在 2-3 个季节中占优势,且其优势度指 数与生态位宽度指数处于中等水平,生态适应幅度小于前一类 (表 2 , 图 3 ), 而与第三类相比,这一类在研究 水库中也具有较强的竞争力。

第三类为窄生态位优势种, 为剩余的 9 种,包括 4 种蓝藻、 2 种绿藻、 1 种硅藻和 2 种隐藻, 仅在某一季节 占优势, 对水温、营养条件等生态因子依赖性较高, 竞争力较小, 利用资源和适应环境的能力相对较弱。就在 研究水库中的竞争力而言,相对较强的前两类的 7 个种中,有 5 种蓝藻,蓝藻的优势不言而喻。

\section{4 优势种生态位重叠}

生态位重叠 (niche overlap) 表示物种间对资源利用的相似性,反映不同物种对同一资源的共同利用程度, 也体现了物种的空间分布情况 ${ }^{[14,45]}$ 。生态位重叠值 $S O_{i j}$ 表示 $\mathrm{i}$ 种群占用 $\mathrm{j}$ 种群资源的大小,亦即 $\mathrm{j}$ 种群被 $\mathrm{i}$ 种 群侵占的资源量。一般情况下,生态位宽度与生态位重叠表现为正相关; $\Delta S O_{i j}$ 的正负表明处于发展或衰退状 态, $\Delta S O_{i j}$ 差值大小表示发展或衰退的程度, $\Delta S O_{i j}$ 为 0 时表明是一个中性种 ${ }^{[2,14,18]}$ 。

本研究中, 较大的生态位宽度大多伴随着较高的 $S O_{i j}$ 值, 符合一般规律 ${ }^{[29]}$ 。从全年来看, 16 个优势种中 9 种处于发展状态, $\Delta S O_{i j}$ 正值最大为小球藻(种 $14,133.6$, 图 4), 生态位重叠最大的则是拟鱼腥藻 (种 $8,-203.4$, 
图 4)。四个季节的当季优势种 $\Delta S O_{i j}$ 多数大于 0 , 处于发展状态, 其中 $\Delta \mathrm{SO}_{i j}$ 正值最大的是冬季的小球藻 (种 $13,81.4)$, 相关分析显示小球藻密度与 TP 显著正相关 $(R=0.395, P<0.01)$, 冬季的高 TP 条件 $((0.896 \pm$ $0.533) \mathrm{mg} / \mathrm{L}$, 表 4) 适宜其生长, 表现出最强的发展状态; 少量当季优势种处于衰退状态, 以秋季拟柱孢藻 (种 $2,-28.6$, 图 4) 负值最大, 可能与秋季氮磷比高 $\left((51.7 \pm 52.1)\right.$, 表 4) 有关, 拟柱孢藻为固氮蓝藻 ${ }^{[46]}$, 高氮磷比 限制了其在秋季的发展。作为唯一的四季优势种, 湖泊假鱼腥藻 $\Delta S O_{i j}$ 与其生态位宽度季节变化类似, 春季最 高(种 $1,34.2$, 图 4), 秋季最低(种 $1,15.6$, 图 4), 也是由于水温的季节变化而引起 ${ }^{[19,44]}$ 。

与其他优势种之间的生态位重叠程度 ( $\Delta S O_{i j}$ 绝对值) 最大的种类 $\Delta S O_{i j}$ 均为负值 (图 4), 说明与其他种群 资源需求相似性最强的种群往往处于衰退状态, 且衰退空间较大 ${ }^{[2]}$ 。当共享资源丰富时,物种间的生态位重 叠只表明种间的生态相似性; 共享资源不足的情况下, 生态位重叠则还暗示着二者存在竞争 ${ }^{[47]}$ 。在研究的 10 个水库中, 冬季物种间生态位重叠值 ( $\Delta S O_{i j}$ 绝对值) 普遍较高 (图 4), 其可能原因: 由于冬季低温不适合大部 分优势藻类的发展, 当资源 (即水温等) 不足时, 一方面大部分藻类生长缓慢, 密度降低, 另一方面生态位重叠 的物种间在环境相对适宜的点位上发生竞争, 导致优势种生态位宽度降低, 物种间生态位重叠加剧 ${ }^{[13,19]}$ 。本 研究数据显示, 冬季的 7 个优势藻种, 有 5 个种 (湖泊假鱼腥藻、短小塔胞藻、小环藻 Cyclotella sp. 、啮噬隐藻 Cryptomonas erosa 、尖尾蓝隐藻Chroomonas acuta) 有超过 $90 \%$ 的数量分布在 50\%的采样点中, 点位竞争激烈, 其生态位宽度也低于其余 2 个物种 (二形栅藻、小球藻) (图 3)。

$\Delta S O_{i j}$ 表征物种与他种竞争的结果, 生态位宽度代表种群在群落中的生态优势程度, 利用速率 $(R)$ 将二者 结合, 可用以衡量物种对生境的生态响应, 指示优势种种群发展性或衰退性强弱 ${ }^{[2,17]}$ 。四个季节当季优势种 中发展性最强的多为蓝藻 (图 4) : 夏季为微小平裂藻, 秋季为大螺旋藻 (Spirulina major), 冬季为短小塔胞藻 (Pyramimonas nanella), 春季则是卷曲鱼腥藻 (Anabaena circinalis)。从全年数据来看, 发展性最强的仍然为蓝 藻, 其中湖泊假鱼腥藻 $R$ 值最高 $(0.100)$, 其次为卷曲鱼腥藻 $(0.061)$ 和细浮鞘丝藻 $(0.015)$, 而尖尾蓝隐藻衰 退性最强 $(-0.035)$ 。在与泊假鱼腥藻、卷曲鱼腥藻等的持续竞争中, 处于衰退状态的种类生态空间会有逐渐 缩小的趋势 (例如尖尾蓝隐藻), 而湖泊假鱼腥藻的优势度可能会进一步的扩大, 甚至发生水华。湖泊假鱼腥 藻、卷曲鱼腥藻等发展性最强的种类具有产毒潜力 ${ }^{[48-50]}$, 而衰退性的种类大多不产毒, 如微小平裂藻、尖尾蓝 隐藻等 ${ }^{[51]}$ 。一旦发生产毒蓝藻水华, 该地区水库的水质安全和水体功能将遭遇严峻考验。

\section{5 优势种种间联结性}

群落物种间的总体关联性反映了群落演替的进行阶段和群落的稳定性,一般而言, 随着演替的持续进行, 群落结构将逐渐趋于完善和稳定, 种间关系也将从负关联逐步趋向于正关联, 直至种间达到稳定共存的局 面 ${ }^{[30]}$ 。在同一环境中, 种对间的正关联指示着对某一方或双方有利的相互作用 ${ }^{[52]}$, 负联结则表明不利于某 一方或双方的相互作用 ${ }^{[30]}$ 。

方差比率 (Variance ratio, VR) 值为优势种的关联指数, 全年 16 个优势种总体 VR 大于 1 , 且统计量 $W$ 大 于 $\chi_{0.05}^{2}(d f)$ (表 5), 表明浮游植物优势种间大致表现出净的正联结。卡方检验的结果显示 (图 5 ), 在全年 16 个优势种 240 个种对内, 联结性显著的有 37 对 $(P<0.05)$, 关联的显著率为 $15.42 \%$, 正负关联比为 3.1 , 大于 1 , 其中极显著正联结 19 对 $(P<0.01$, 且 $\mathrm{ad}>\mathrm{bc})$, 显著正联结 9 对 $(P<0.05$, 且 $\mathrm{ad}>\mathrm{bc})$; 极显著负联结 6 对 $(P<$ 0.01 , 且 $\mathrm{ad}<\mathrm{bc})$, 显著负联结 3 对 $(P<0.05$, 且 $\mathrm{ad}<\mathrm{bc})$ 。种对间正负关联比大于 1 , 研究水库全年优势种间总 体关联性呈现显著正联结, 正负关联比也大于 1 , 表明该地区水库群落结构较为稳定且存在正向演替的趋势, 与环境条件较为适应 ${ }^{[2]}$ 。

16 个优势种中有 25 个种对存在显著正关联, 与其他相关研究 ${ }^{[4]}$ 相比, 正关联显著率较高, 暗示了本研究 浮游植物群落中物种优势度对物种关联的影响较为显著。

分季节看, 4 个季节除夏季表现为显著负关联外,其余 3 个季节均为显著正关联 (表 5 )。负关联表明夏 季浮游植物群落比较脆弱, 结构简单, 易发生波动甚至退化, 这可能与夏季大量降雨与水库开闸泄洪导致的水 环境剧烈变化有关 ${ }^{[24-25]}$, 此时浮游植物群落结构稳定性较差, 但仍表现为蓝藻的发展状态 (夏季 6 种优势蓝 
I当季优势种 口当季不占优势的种类 $\square$ 全部优势种

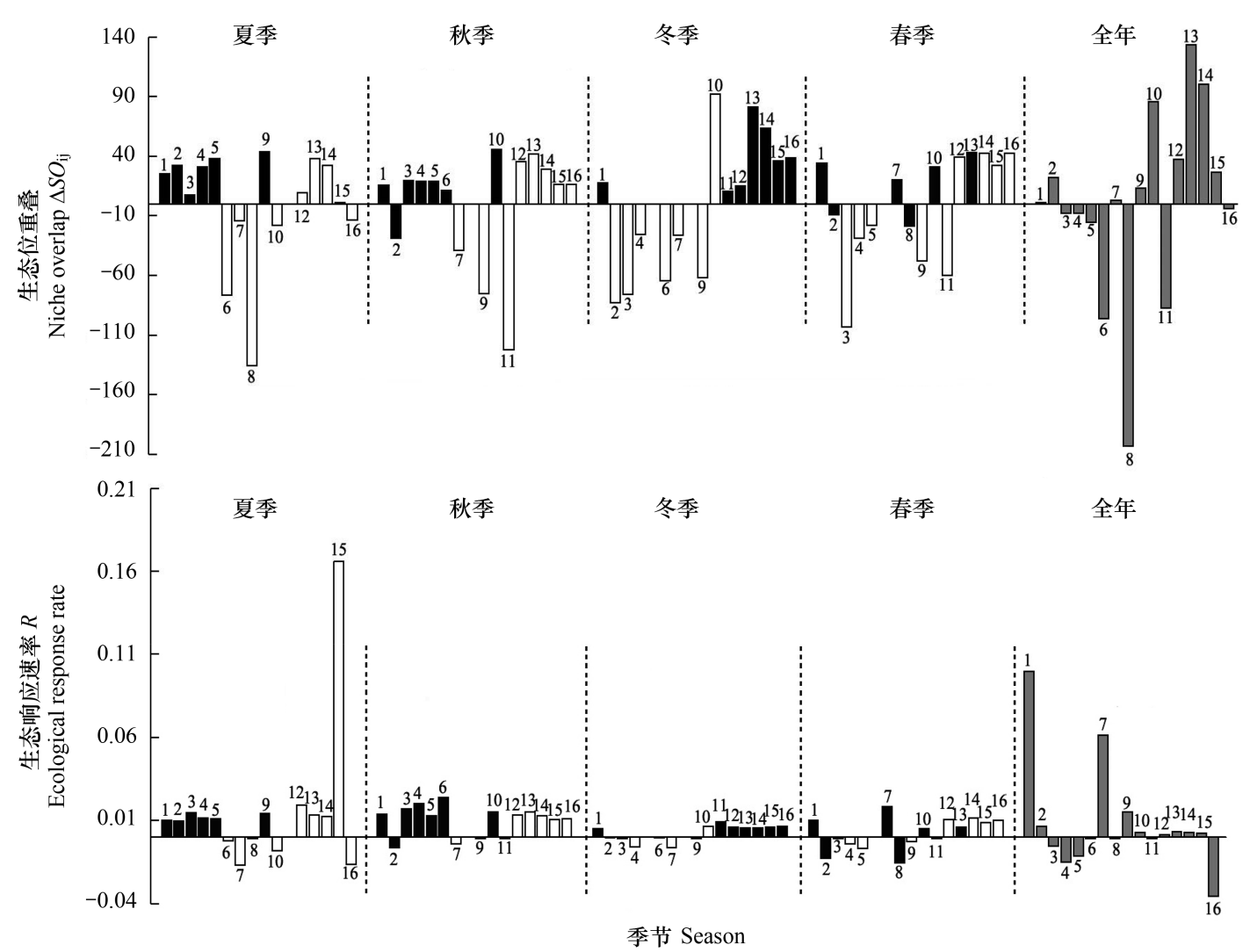

图 4 研究水库浮游植物优势种生态位重叠 $\left(\Delta S O_{i j}\right)$ 和生态响应速率 $(R)$

Fig.4 Niche overlap $\left(\Delta S O_{i j}\right)$ and ecological response rate $(R)$ of dominant phytoplankton species

藻 $\Delta S O_{i j}>0$, 图 4)。夏季浮游植物群落结构的不稳定性, 结合目前已经出现的蓝藻高密度、高优势度与高生态 响应速率, 可以预测本区域中小型水库夏季出现间断性蓝藻水华的可能性较大,尤其可能出现假鱼腥藻水华。

表 5 浮游植物优势种总体关联性

Table 5 General interspecific association of dominant phytoplankton species

\begin{tabular}{lccccc}
\hline $\begin{array}{l}\text { 季节 } \\
\text { Season }\end{array}$ & $\begin{array}{c}\text { 方差比率 } \\
\text { Variance ratio }\end{array}$ & $\begin{array}{c}\text { 检验统计量 } W \\
\text { Test statistics } W\end{array}$ & $d f$ & $\begin{array}{c}\mathrm{c} \text { 临界值 }\left[\chi_{0.95}^{2}, X_{0.05}^{2}\right] \\
\text { Critical value }\end{array}$ & $\begin{array}{c}\text { 校验结果 } \\
\text { Verification results }\end{array}$ \\
\hline 夏季 summer & 0.91 & 26.41 & 5 & {$[1.15,11.07]$} & 显著负关联 \\
秋季 Autumn & 3.01 & 84.15 & 6 & {$[1.64,12.59]$} & 显著正关联 \\
冬季 Winter & 1.29 & 33.67 & 6 & {$[1.64,12.59]$} & 显著正关联 \\
春季 Spring & 2.25 & 53.89 & 5 & {$[1.15,11.07]$} & 显著正关联 \\
全年 All year & 2.26 & 241.62 & 15 & {$[7.26,25.00]$} & 显著正关联 \\
\hline
\end{tabular}

\section{6 川东水库蓝藻发展与预测}

研究水库中, 不论是优势种种类数、优势度指数以及细胞密度, 蓝藻始终占据优势地位, 尤其是假鱼腥藻, 其优势度指数全年最高, 夏季平均密度高达 $1.84 \times 10^{8}$ 个/L, 明显高于同类型其他水体 ${ }^{[33-54]}$ 。从发展性来看, 假鱼腥藻四季生态位重叠值均大于零, 生态响应速率为 16 种中最高, 说明其全年均为发展状态且发展性最 强, 处于不断掠夺其他物种资源的扩张状态。其他几种蓝藻,包括拟短形颤藻、拉氏拟柱孢藻、卷曲鱼腥藻、细 浮鞘丝藻等也具有较为明显的数量优势或发展优势。研究水库种间关联整体较稳定, 可在全年大部分时间维 持目前的状态, 即蓝藻优势, 这是由于四川丘陵区人口众多, 农业发达, 随地表径流进人各类水体的大量营养 
物质导致其富营养化程度增加 ${ }^{[55-56]}$, 有利于蓝藻的生 存与发展。同时夏季由于大量降水和开闸泄洪导致的 环境剧烈变化 ${ }^{[24-25]}$, 出现了浮游植物群落结构的不稳 定,但并不影响蓝藻的优势地位。故而研究水库在夏季 很可能发生间断性的、以丝状蓝藻 (假鱼腥藻、鱼腥藻、 颤藻等) 为优势的蓝藻水华。

\section{3 结论}

(1) 研究期间共检出浮游植物 188 种; 四季共出现 4 门 16 个优势种, 其中蓝藻 9 种, 竞争力相对较强的 7 种藻类中有 5 种蓝藻, 分别是湖泊假鱼腥藻、阿氏拟柱 狍藻、微小平裂藻、拟短形颤藻、中华小尖头藻; 以蓝藻 的现存量为最高。

(2) 冬季物种间生态位重叠值在四季中较高; 不同 季节优势种中发展性最强的多为具有产毒潜力的蓝藻, 存在发生有毒蓝藻水华的风险; 水温、营养条件等环境 因子对优势种生态位宽度、种间生态位重叠值等有明显 影响。

(3) 全年群落种间总体关联性结果表明该地区水 库群落结构较为稳定且存在正向演替的趋势; 在夏季出

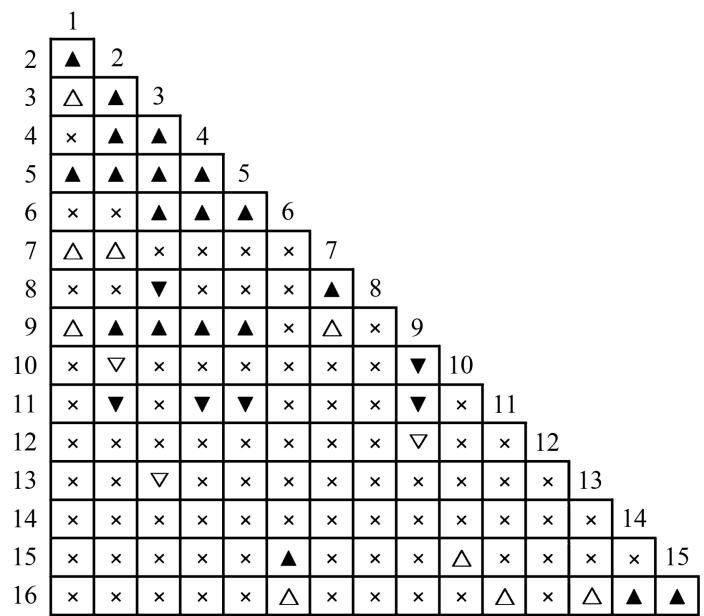

图 $5 \chi^{2}$ 检验半矩阵图

Fig.5 Half matrix of the association coefficients $\chi^{2}$ test among the dominant phytoplankton species

$\Delta$ : 极显著正相关 $(P<0.01)$, 且 $\mathrm{ad}>\mathrm{bc} ; \triangle$ : 显著正相关 $(P<0$. $05)$, 且 $a d>b c ; \nabla$ : 极显著负相关 $(P<0.01)$,且 $a d<b c ; \nabla$ :显著负 相关 $(P<0.01)$, 且 $a d<b c ; \times$ : 不显著相关 $(P>0.05)$ 。其中, $a$ 为 两个相联结的藻种均出现的样方数, $b 、 c$ 为只有一种物种出现的 样方数, $\mathrm{d}$ 为两物种均未出现的样方数; 数字为优势种编号 现了浮游植物群落结构的不稳定,但四季均表现为蓝藻的发展状态。

综上所述,四川丘陵地区中小型水库夏季出现间断性有毒蓝藻水华的风险性高,需开展有效水质管理与 水体修复。

致谢: 内江师范学院生命科学学院张甜、刘天凤、贺雪、李文星、胡琼瑶、段炼同学在野外采样工作和样品处理 中给予协助,特此致谢。

\section{参考文献 (References) :}

[1 ] 张金屯. 数量生态学(第二版). 北京: 科学出版社, 2011 .

[ 2 ] 杨文焕, 申涵, 周明利, 李卫平, 张生. 包头南海湖浮游植物优势种生态位及种间联结性季节分析. 中国环境科学, 2020, 40(1)： 383-391.

[ 3 ] 宋永昌. 植被生态学(第二版). 北京: 高等教育出版社, 2017.

[ 4 ] 梁士楚, 李铭红. 生态学. 武汉: 华中科技大学出版社, 2015.

[ 5 ] 张桂莲, 张金屯. 关帝山神尾沟优势种生态位分析. 武汉植物学研究, 2002, 20(3): 203-208.

[ 6 ] Álvarez-Yépiz J C, Búrquez A, Dovčiak M. Ontogenetic shifts in plant-plant interactions in a rare cycad within angiosperm communities. Oecologia, $2014,175(2): 725-735$.

[ 7 ] Litchman E, Edwards K F, Klausmeier C A, Thomas M K. Phytoplankton niches, traits and eco-evolutionary responses to global environmental change. Marine Ecology Progress Series, 2012, 470: 235-248.

[ 8 ] Weithoff G, Beisner B E. 2019. Measures and approaches in trait-based phytoplankton community ecology-from freshwater to marine ecosystems. Frontiers in Marine Science, 2019, 6: 40.

[ 9 ] da Silva M N, Granzotti R V, de Carvalho P, Rodrigues L C, Bini L M. Niche measures and growth rate do not predict interspecific variation in spatial synchrony of phytoplankton. Limnology, 2020, 22(1): 121-127.

[10］邓贤兰, 曹裕松, 梁琴, 龙婉婉. 井冈山山顶矮林乔木层优势种的生态位研究. 植物资源与环境学报, 2016, 25(1): 88-93.

[11] Zhong Y P, Liu X, Xiao W P, Laws E A, Chen J X, Wang L, Liu S G, Zhang F, Huang B Q. Phytoplankton community patterns in the Taiwan Strait match the characteristics of their realized niches. Progress in Oceanography, 2020, 186: 102366.

[12] Karasiewicz S, Breton E, Lefebvre A, Hernández Fariñas T, Lefebvre S. Realized niche analysis of phytoplankton communities involving HAB: 
Phaeocystis spp. as a case study. Harmful Algae, 2018, 72:1-13.

[13] 郑挺. 北部湾北部浮游植物若干生态特征 [D ]. 厦门: 厦门大学, 2014

[14] Xiao W P, Wang L, Laws E, Xie Y Y, Chen J X, Liu X, Chen B Z, Huang B Q. Realized niches explain spatial gradients in seasonal abundance of phytoplankton groups in the South China Sea. Progress in Oceanography, 2018, 162: 223-239.

[15] Flombaum P, Wang W L, Primeau F W, Martiny A C. Global picophytoplankton niche partitioning predicts overall positive response to ocean warming. Nature Geoscience, 2020, 13(2): 116-120.

[16］王翠红, 张金屯. 汾河水库及河道中优势硅藻生态位的研究. 生态学杂志, 2004, 23(3) : 58-62.

[17］孟东平, 王翠红, 辛晓芸, 张金屯. 汾河太原段水体浮游藻类生态位的研究. 环境科学与技术, 2006, 29(10) : 95-97.

［18］汪志聪, 吴卫菊, 左明, 李敦海. 巢湖浮游植物群落生态位的研究. 长江流域资源与环境, 2010, 19(6) : 685-691.

[19] 徐春燕, 俞秋佳, 徐风洁, 胡雪芹, 由文辉. 淀山湖浮游植物优势种生态位. 应用生态学报, 2012, 23(9) : 2550-2558.

[20] 郭坤, 杨德国, 彭婷, 罗静波, 何勇风, 柴毅. 湖北省长湖浮游植物优势种生态位分析. 湖泊科学, 2016, 28(4): 825-834.

[21］崔元文. 四川紫色土丘陵区不同耕作和覆盖方式下坡地养分流失研究 [D ]. 重庆: 西南大学, 2012.

[22] 张丽萍. 四川省水资源短缺程度及缺水类型综合研究 $[\mathrm{D}]$. 雅安：四川农业大学, 2004.

[23］叶培英, 周渝. 四川省水库工程数量及分布简介. 四川水利, 2013, (S1) : 24-26.

[24] 周丽, 刘合辉, 谢贤健, 刘术良, 范志华. 内江地区 39 年气候变化状况分析. 安徽农业科学, 2011, 39(28)：17479-17482.

[25] 任茜, 牀宏, 贾国君, 王俊, 曹迎. 低山丘陵区土地利用格局优化研究一一以四川省内江市为例. 安徽农业科学, 2010, 38(4)： 2149-2152.

[26] 国家环境保护总局. 水和废水监测分析方法(第四版). 北京: 中国环境科学出版社, 2002: 88-284.

[27] 胡鸿钧, 魏印心. 中国淡水藻类一系统、分类及生态. 北京: 科学出版社, 2006.

[28] 章宗涉, 黄祥飞. 淡水浮游生物研究方法. 北京: 科学出版社, 1991.

[29] 狄晓艳, 李素清. 晋西皇姑梁小流域人工植物群落优势种生态位和种间关系研究. 干旱区资源与环境, 2017, 31(12): 179-183.

[30] 徐满厚, 刘敏, 翟大形, 刘夰. 植物种间联结研究内容与方法评述. 生态学报, 2016, 36(24): 8224-8233.

[31] 于飞, 何冬琼, 张秋劲, 刘佳, 徐亮. 升钟水库富营养状况及生物群落调查评价. 四川环境, 2012, 31(1): 76-81.

[32] 何冬琼, 张秋劲, 刘佳, 于飞, 徐亮. 升钟水库浮游植物的生物多样性调查及时空分布. 中国环境监测, 2013，29(1): 30-33.

[33］杨敏, 张晟, 刘朔孺. 草街水库蓄水后嘉陵江浮游植物群落特征及水质评价. 环境科学, 2015, 36(7): 2480-2486.

[34] 邓金燕. 水利开发对二滩水库浮游植物及水质状况季节性影响. 水土保持研究, 2016, 23(1) : 349-355.

[35] 张耀文, 李洪, 李嘉, 宋洋, 张陵蕾, 李永, 蒲迅赤, 黄文典. 西南山区典型河道型水库藻类功能群时空演替特征及其影响因素: 以紫坪 铺水库为例. 环境科学, 2018, 39(6): 2680-2687.

[36] 胡莲, 邹曦, 郑志伟, 张志永, 杨晴, 万成炎, 潘晓洁. 三峡水库神农溪浮游植物群落结构及其与环境因子的关系. 水生态学杂志, 2020, $41(6): 27-36$

[37] 金相灿, 屠清瑛. 湖泊富营养化调查规范(第二版). 北京: 中国环境科学出版社, 1990: 286-302.

[38] 况琪军, 马沛明, 胡征宇, 周广杰. 湖泊富营养化的藻类生物学评价与治理研究进展. 安全与环境学报, 2005, 5(2): 87-91.

[39] 陈莎, 谢青, 付梅, 江韬, 王永敏, 王定勇. 三峡库区典型支流水库浮游动植物群落结构特征及其与环境因子的关系. 环境科学, doi : 10 . 13227/j.hjkx.202008263.

［40］沈暳芬, 章宗涉, 龚循矩, 顾曼如, 施之新, 魏印心. 微型生物监测新技术. 北京: 中国建筑工业出版社, 1990: 1-524.

[41］彭松耀, 李新正, 王洪法, 张宝琳. 南黄海春季大型底栖动物优势种生态位. 生态学报, 2015, 35(6): 1917- 1928.

[42] Dolédec S, Chessel D, Gimaret-Carpentier C. Niche separation in community analysis: a new method. Ecology, 2000, 81(10): $2914-2927$.

[43] 王刚, 赵松岭, 张鹏云, 陈庆诚. 关于生态位定义的探讨及生态位重叠计测公式改进的研究. 生态学报, 1984, 4(2): 119-127.

[44] 王得玉, 冯学智, 周立国, 郝景燕, 徐晓雄. 太湖蓝藻爆发与水温的关系的 MODIS 遥感. 湖泊科学, 2008, 20(2): 173-178.

[45] 牛慧慧, 陈辉, 付阳, 杨祎, 张斯琦, 张博雄. 柴达木盆地东部荒漠植物生态位特征. 生态学报, 2019, 39(8): 2862-2871.

[46] 雷腊梅, 雷敏婷, 赵莉, 阮紫犧, 于婷, 彭亮, 韩博平. 人侵蓝藻一一拟柱胞藻的分布特征及生理生态研究进展. 生态环境学报, 2017, 26(3): 531-537

[47] 钟宇, 张健, 刘泉波, 杨万勤, 吴福忠, 冯茂松. 巨桉人工林草本层主要种群的生态位分析. 草业学报, 2010, 19(4): 16-21.

[48] Carmichael W W. The cyanotoxins. Advances in Botanical Research, 1997, 27: 211-256.

[49] Marsalek B, Blaha L, Babica P. Analyses of microcystins in the biomass of Pseudanabaena linmnetica collected in Znojmo reservoir. Czech Phycology, 2003, 3: 195-197.

[50] Nguyen L T T, Cronberg G, Moestrup Ø, Daugbjerg N. Annamia toxica gen. et sp. nov. (Cyanobacteria), a freshwater cyanobacterium from Vietnam that produces microcystins: ultrastructure, toxicity and molecular phylogenetics. Phycologia, 2013, 52(1) : 25-36.

[51] 辛艳萍, 韩博平, 雷腊梅, 林秋奇. 两座抽水型水库蓝藻种群与微囊藻毒素的比较分析. 热带亚热带植物学报, 2010, 18(3): 224-230.

[52］郭俊兵, 狄晓艳, 李素清. 山西大同矿区煤䂥石山自然定居植物群落优势种种间关系. 生态学杂志, 2015, 34(12): 3327-3332.

[53] 龙胜兴, 叶晓云, 俞振兴, 陈橡, 刘之威. 2011 年红枫湖水库浮游植物群落结构分布特征. 贵州师范大学学报: 自然科学版, 2012, 30 (5) : 9-13, 35-35.

[54] 林秋奇, 雷腊梅, 韩博平. 南亚热带不同营养水平水库的蓝藻组成与动态. 生态学杂志, 2007, 26(7) : 1027-1033.

[55] 纪丁愈, 王庆安, 余红英, 王东睿, 张翔. 川中丘陵地区小流域农业面源污染特征及水环境容量研究——黄腊溪小流域为例. 水资源 与水工程学报, 2011, 22(4): 81-84.

[56] 陈尚洪, 张晴雯, 陈红琳, 郑盛华, 吴铭, 梅旭荣, 刘定辉. 四川丘陵农区地表水水质时空变化与污染现状评价. 农业工程学报, 2016, 32(S2) : 52-59. 